\title{
Decreased pro-inflammatory cytokine production by LPS-stimulated PBMC upon in vitro incubation with the flavonoids apigenin, luteolin or chrysin, due to selective elimination of monocytes/macrophages
}

\author{
Sander Hougee ${ }^{\mathrm{a}, *}$, Annemarie Sanders ${ }^{\mathrm{a}}$, Joyce Faber ${ }^{\mathrm{a}}$, Yvo M.F. Graus ${ }^{\mathrm{a}}$, \\ Wim B. van den Berg ${ }^{\mathrm{b}}$, Johan Garssen ${ }^{\mathrm{a}}$, H. Friso Smit ${ }^{\mathrm{a}}$, Maarten A. Hoijer ${ }^{\mathrm{a}}$ \\ ${ }^{a}$ Numico-Research, P.O. Box 7005, Wageningen 6700, The Netherlands \\ ${ }^{\mathrm{b}}$ Experimental Rheumatology and Advanced Therapeutics, University Medical Center Nijmegen, \\ Nijmegen, The Netherlands
}

Received 29 June 2004; accepted 7 October 2004

\begin{abstract}
Apigenin and its structural analogues chrysin and luteolin were used to evaluate their capacity to inhibit the production of proinflammatory cytokines by lipopolysaccharide (LPS)-stimulated human peripheral blood mononuclear cells (PBMC). Furthermore, flowcytometric analysis was performed to compare the effects of apigenin, chrysin, luteolin, quercetin and naringenin on the different cell types present in PBMC.

LPS-stimulated PBMC were cultured in the presence of the flavonoids and TNF $\alpha$, IL- $1 \beta$ and IL- 6 were measured in the supernatants. In parallel, metabolic activity of the PBMC was determined by measuring succinate dehydrogenase activity. Apigenin, chrysin and luteolin dose-dependently inhibited both pro-inflammatory cytokine production and metabolic activity of LPS-stimulated PBMC. With increasing concentration of apigenin, chrysin or luteolin the monocytes/macrophages disappeared as measured by flowcytometry. This also appeared to occur in the non-LPS-stimulated PBMC. At the same time there was an increase in dead cells. T- and B-lymphocytes were not affected. Quercetin and naringenin had virtually no effects on cytokines, metabolic activity or on the number of cells in the studied cell populations.

In conclusion, monocytes were specifically eliminated in PBMC by apigenin, chrysin or luteolin treatment in vitro at low concentrations (around $8 \mu \mathrm{M}$ ), in which apigenin appeared to be the most potent.
\end{abstract}

(C) 2004 Elsevier Inc. All rights reserved.

Keywords: Flavonoids; Apigenin; Pro-inflammatory; Metabolic activity; PBMC

\section{Introduction}

Inflammatory processes are orchestrated by inflammatory cells through a complex set of chemical signals and can arise in any tissue in response to traumatic, infectious, post-ischaemic, toxic, allergic and/or auto-immune injury. In chronic inflammatory diseases, however, the injury persists, leading to tissue damage. In the search for antiinflammatory agents, suitable for nutritional purposes,

\footnotetext{
Abbreviations: LPS, lipopolysaccharide; TNF, tumor necrosis factor; IL, interleukin; PBMC, human peripheral blood mononuclear cells; DMSO, dimethylsulfoxide; D-PBS, Dulbecco's phosphate-buffered saline

* Corresponding author. Tel.: +31 317 467800; fax: +31 317466500 .

E-mail address: sander.hougee@ numico-research.nl (S. Hougee).
}

botanicals are of specific interest. Natural products with an alleged anti-inflammatory activity have been used in traditional medicine and are increasingly subject of investigation for their biological activity, to confirm their role in the prevention and treatment of inflammatory diseases. One group of molecules that has been shown to affect inflammation is flavonoids.

Flavonoids, a group of phenolic phytochemicals, are common in vascular plants and are abundant in particular spices, vegetables and fruits. They are considered important constituents in the human diet, although their daily intake varies with dietary habits. Several properties have been ascribed to flavonoids. Among them are antioxidant activity because of radical scavenging abilities [1-4], 
<smiles>[R5]c1cc([C@@H]2Oc3cc([R5])c([2H])c([R5])c3C(=O)C2[R5])c([R2])c([Z8])c1[R6]</smiles>

Fig. 1. Flavonoid basic structure. Flavonoids are divided in different subclasses. In this study, flavonoids from three different classes are used: flavanones, single bond at $\mathrm{C} 2-3$; flavones, double bond at $\mathrm{C} 2-3$ and $\mathrm{R}_{3}$ is $\mathrm{H}$; flavonols, double bond at $\mathrm{C} 2-3$ and $\mathrm{R}_{3}$ is $\mathrm{OH}$.

anticancer [5,6] and anti-proliferative effects [7-10], immunomodulatory, and particularly, anti-inflammatory effects [11-14]. The ability of certain flavonoids to inhibit pro-inflammatory mediators could be useful in the treatment of several chronic inflammatory diseases.

As an example, apigenin that belongs to the subclass flavones (see Fig. 1; Table 1), has previously been described to inhibit the inflammatory mediators nitric oxide and prostaglandin $\mathrm{E}_{2}$. Their respective enzymes inducible nitric oxide synthase (iNOS) and cyclooxygenase (COX) are significantly impaired in an in vitro model using two different murine macrophage cell-lines (RAW 264.7 and J774 A.1) that are activated with LPS $[12,13]$.

Both iNOS and COX are enzymes that play a crucial role in inflammation. In the onset of inflammation, however, affected tissue abounds with pro-inflammatory cytokines. In the initiation and development of e.g. rheumatoid arthritis (RA) and osteoarthritis (OA) disease processes, pro-inflammatory cytokines are thought to play a pivotal role $[15,16]$.

TNF $\alpha$, IL-1 $\beta$ and IL-6 are pro-inflammatory cytokines and are important in the inflammatory stages of several chronic inflammatory diseases. For example, RA and OA, both chronic joint diseases, share the characteristics of an inflamed synovium during certain stages of the disease.
During inflammation, the synovium is infiltrated with mononuclear cells [17], producing a range of inflammatory mediators, including pro-inflammatory cytokines. TNF $\alpha$ and IL- $1 \beta$ are important catabolic factors of which IL- $1 \beta$ is the most devastating, in terms of inhibiting cartilage formation by chondrocytes and enhancing cartilage breakdown by upregulating the production of several matrix metalloproteases. TNF $\alpha$ is thought to be an important driving force of IL-1 synthesis [18]. IL-6 is thought to be involved in the inflammation process, rather than the cartilage destruction process, because studies in experimental arthritis in IL-6-deficient mice revealed reduced joint inflammation, although the cartilage destruction was not inhibited [19]. When certain flavonoids appear to be capable of inhibiting the production of the above-mentioned pro-inflammatory cytokines, they could be of potential use as anti-inflammatory agents in chronic inflammatory diseases such as RA or OA.

In the present study, the possible anti-inflammatory effect of apigenin and apigenin structure analogues have been investigated in vitro in order to evaluate whether these flavonoids have potential as anti-inflammatory agents in chronic inflammatory diseases. The production of the proinflammatory cytokines TNF $\alpha$, IL- $1 \beta$ and IL- 6 by LPSstimulated PBMC after incubation with flavonoids was determined. In parallel, metabolic activity of the PBMC was measured. Finally, it was analyzed using flowcytometry whether the flavonoids have selective effects on the three major cell populations in PBMC (monocytes/macrophages, T-lymphocytes and B-lymphocytes).

\section{Materials and methods}

\subsection{Flavonoids}

All flavonoids were obtained from Indofine Chemical Company except for baicalein that was purchased from Sigma. All flavonoids were dissolved freshly prior to use in DMSO and were kept in the dark.

Table 1

Flavonoid structures, class and IC50 for TNF $\alpha$, IL-1 $\beta$ and IL-6 inhibition in $16 \mathrm{~h}$ LPS-stimulated PBMC

\begin{tabular}{|c|c|c|c|c|c|c|c|c|c|c|c|c|}
\hline \multirow[t]{2}{*}{ Flavonoid } & \multirow[t]{2}{*}{ Class } & \multicolumn{4}{|c|}{ Flavonoid structures } & \multicolumn{7}{|c|}{ IC50 \pm S.D. $(\mu \mathrm{M})$} \\
\hline & & $\mathrm{R}_{3}$ & $\mathrm{R}_{5}$ & $\mathrm{R}_{6}$ & $\mathrm{R}_{7}$ & $\overline{\mathrm{R}_{2}^{\prime}}$ & $\mathrm{R}_{3}^{\prime}$ & $\mathrm{R}_{4}^{\prime}$ & $\Delta^{2-3}$ & $\mathrm{TNF} \alpha$ & IL-1 $\beta$ & IL-6 \\
\hline Apigenin & Flavone & $\mathrm{H}$ & $\mathrm{OH}$ & $\mathrm{H}$ & $\mathrm{OH}$ & $\mathrm{H}$ & $\mathrm{H}$ & $\mathrm{OH}$ & $=$ & $8.9 \pm 2.2$ & $5.3 \pm 0.7$ & $4.8 \pm 0.2$ \\
\hline Chrysin & Flavone & $\mathrm{H}$ & $\mathrm{OH}$ & $\mathrm{H}$ & $\mathrm{OH}$ & $\mathrm{H}$ & $\mathrm{H}$ & $\mathrm{H}$ & $=$ & $17.8 \pm 1.7$ & $10.7 \pm 2.0$ & $10.8 \pm 1.2$ \\
\hline Luteolin & Flavone & $\mathrm{H}$ & $\mathrm{OH}$ & $\mathrm{H}$ & $\mathrm{OH}$ & $\mathrm{H}$ & $\mathrm{OH}$ & $\mathrm{OH}$ & $=$ & $7.9 \pm 4.6$ & $5.1 \pm 0.4$ & n.d. \\
\hline Kaempferol & Flavonol & $\mathrm{OH}$ & $\mathrm{OH}$ & $\mathrm{H}$ & $\mathrm{OH}$ & $\mathrm{H}$ & $\mathrm{H}$ & $\mathrm{OH}$ & $=$ & $>20$ & $>20$ & $>20$ \\
\hline Naringenin & Flavanone & $\mathrm{H}$ & $\mathrm{OH}$ & $\mathrm{H}$ & $\mathrm{OH}$ & $\mathrm{H}$ & $\mathrm{H}$ & $\mathrm{OH}$ & - & $>20$ & $>20$ & $>20$ \\
\hline Quercetin & Flavonol & $\mathrm{OH}$ & $\mathrm{OH}$ & $\mathrm{H}$ & $\mathrm{OH}$ & $\mathrm{H}$ & $\mathrm{OH}$ & $\mathrm{OH}$ & $=$ & $>20$ & $>20$ & $>20$ \\
\hline Morin & Flavonol & $\mathrm{OH}$ & $\mathrm{OH}$ & $\mathrm{H}$ & $\mathrm{OH}$ & $\mathrm{OH}$ & $\mathrm{H}$ & $\mathrm{OH}$ & $=$ & $>20$ & $>20$ & $>20$ \\
\hline Scutellarein & Flavone & $\mathrm{H}$ & $\mathrm{OH}$ & $\mathrm{OH}$ & $\mathrm{OH}$ & $\mathrm{H}$ & $\mathrm{H}$ & $\mathrm{OH}$ & $=$ & $>20$ & $>20$ & $>20$ \\
\hline Cosmosiin & Flavone & $\mathrm{H}$ & $\mathrm{OH}$ & $\mathrm{H}$ & $O$-glucose & $\mathrm{H}$ & $\mathrm{H}$ & $\mathrm{OH}$ & $=$ & $>20$ & $>20$ & $>20$ \\
\hline Baicalein & Flavone & $\mathrm{H}$ & $\mathrm{OH}$ & $\mathrm{OH}$ & $\mathrm{OH}$ & $\mathrm{H}$ & $\mathrm{H}$ & $\mathrm{H}$ & $=$ & $>20$ & $>20$ & $>20$ \\
\hline
\end{tabular}

For basic structure flavonoid see Fig. $1 . \Delta^{2-3}=$ means double bond; $\Delta^{2-3}-$ means single bond at $\mathrm{C} 2-3$; $>20$ : no inhibition observed below $20 \mu \mathrm{M}$; n.d.: not determined. Data shown are the average IC50 of four human donors \pm S.D. 


\subsection{PBMC isolation}

PBMC from healthy donors were obtained from buffy coats supplied by the Sanquin Bloodbank of Nijmegen (informed consent was obtained by the blood bank) and prepared by Ficoll gradient centrifugation. In short, $10 \mathrm{ml}$ of Ficoll-Paque ${ }^{\circledR}$ (Amersham Pharmacia Biotech) was stratified under $20 \mathrm{ml}$ of peripheral blood and centrifugation was performed at $400 \times g$ for $20 \mathrm{~min}$ at room temperature (RT). Recovered PBMC were washed three times

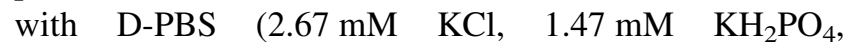
$137.93 \mathrm{mM} \mathrm{NaCl}, 8.06 \mathrm{mM} \mathrm{Na} \mathrm{HPO}_{4} \cdot 7 \mathrm{H}_{2} \mathrm{O}$, Invitrogen) containing $2 \%$ heat-inactivated fetal calf serum $\left(\mathrm{FCS}^{\mathrm{hi}}\right)$. Cells were cultured in RPMI-1640 culture medium containing $25 \mathrm{mM}$ HEPES and $2 \mathrm{mM}$ L-glutamine enriched with $100 \mathrm{U} / \mathrm{ml}$ penicillin/streptomycin, $1.0 \mathrm{mM}$ sodiumpyruvate and $10 \% \mathrm{FCS}^{\text {hi }}$ and were counted with a Coulter Counter $^{\circledR}$. Cell viability was checked with trypan blue staining under the microscope. The cell concentration was brought to $1 \times 10^{6}$ cells $/ \mathrm{ml}$ culture medium. For all experiments, freshly isolated PBMC were used.

\subsection{Incubation of flavonoids with PBMC and subsequent stimulation with LPS}

Flavonoids were tested for their effect on the production of pro-inflammatory cytokines by LPS-stimulated PBMC. Flavonoids were dissolved in DMSO and diluted in cell culture medium. The final concentration of DMSO at the cells was $0.1 \%$. In control experiments, this concentration did not show any effects on the measured parameters. Concentration ranges of flavonoids were pipetted into a flat bottom 96-wells culture plate (Costar Corning), $20 \mu \mathrm{l}$ per well. PBMC were added $\left(150 \mu 1,1 \times 10^{6}\right.$ cells $\left./ \mathrm{ml}\right)$ and flavonoids and PBMC were pre-incubated for 1 -h at $37{ }^{\circ} \mathrm{C}$ in a humidified environment containing $5 \% \mathrm{CO}_{2}$. LPS $(E$. Coli, O55:B5, Sigma) was added (30 $\mu \mathrm{l} /$ well, $10 \mathrm{ng} / \mathrm{ml})$ and the cells were subsequently incubated for another $16 \mathrm{~h}$. Supernatants were harvested and stored at $-80{ }^{\circ} \mathrm{C}$ until analysis for cytokines.

\subsection{Metabolic activity}

WST-1 (4-[3-(4-iodophenyl)-2-(4-nitrophenyl)-2H-5tetrazolio]-1,3-benzene disulfonate, Roche Diagnostics) is a substrate for the enzyme succinate dehydrogenase. The conversion product formazan can be measured at $450 \mathrm{~nm}$ with a reference filter at $655 \mathrm{~nm}$. The activity of succinate dehydrogenase reflects mitochondrial activity and may therefore be indicative for metabolic activity and/or cell viability.

After the incubation period of flavonoids and LPSstimulated PBMC, WST-1 was added undiluted (10 $\mu \mathrm{l} /$ well). Absorbance was measured in a plate reader (Ultramark, BioRad), directly after WST-1 addition and after a $5 \mathrm{~h}$ incubation period of the cells. Control values (without flavonoids) were set at $100 \%$, and all values were expressed as percentage of control values.

\subsection{Flowcytometric analysis}

PBMC used in the flowcytometrical analysis were from female healthy human donors with ages of 51, 48, 33, 33 and $26(n=5)$. PBMC were washed with D-PBS and $20 \mu \mathrm{l} /$ well trypsin-EDTA was added (0.05\% trypsin, cat. \#25300, Invitrogen). Cells were incubated for $5 \mathrm{~min}$ at $37^{\circ} \mathrm{C}$ in a humidified environment containing $5 \% \mathrm{CO}_{2}$. PBMC were suspended by carefully repeated pipetting and washed with D-PBS containing $0.5 \%$ BSA (bovine serum albumin, Sigma). Cells were transferred to a 96 -wells polypropylene V-bottom plate (Greiner) and kept on ice for the whole procedure until analysis by flowcytometry. Stainings with phycoerythrin (PE) labeled monoclonal antibodies (mabs) directed against either CD14, CD3 and CD19 or their isotype controls (Beckman Coulter) were performed in a volume of $50 \mu \mathrm{l}$. Mabs were diluted 1:10 in D-PBS/0.5\% BSA and PBMC were incubated for $30 \mathrm{~min}$ in the dark. PBMC were washed and subsequently incubated with annexin V-Fluos (Roche Diagnostics), according to the manufacturer's protocol ( $1 \mu \mathrm{l}$ of annexin V-Fluos in $99 \mu \mathrm{l}$ binding buffer). After an incubation period of $30 \mathrm{~min}$, cells were washed in binding buffer. To the appropiate samples propidium iodide (PI, Molecular Probes) was added ( $1 \mu \mathrm{l}$ of $20 \mu \mathrm{g} / \mathrm{ml}$ PI per sample) after which the samples were ready to be analyzed by flowcytometry.

\subsection{Cytokine ELISA}

TNF $\alpha$, IL- $1 \beta$ and IL- 6 were measured in supernatants of cultured PBMC using ELISA antibody pair kits from Biosource $\left(\right.$ Cytoset $\left.^{\mathrm{TM}}\right)$. ELISAs were performed according to the manufacturer's protocol.

\section{Results}

\subsection{Effects of flavonoids on the production of pro-inflammatory cytokines and metabolic activity in LPS-stimulated PBMC}

The ability of several flavonoids (Fig. 1) to inhibit the production of inflammatory cytokines was tested in LPSstimulated PBMC. Apigenin, chrysin and luteolin all inhibited pro-inflammatory cytokine production of which apigenin and luteolin appeared to be the most potent inhibitors. No inhibition below $20 \mu \mathrm{M}$ was observed with the other flavonoids tested (Table 1). Metabolic activity, measured by the WST-1 assay, was used as a control for actual inhibition of cytokine production. A concentrationdependent decreased metabolic activity of the PBMC was observed upon incubation with apigenin, chrysin and luteolin. The other flavonoids tested had no effect on 


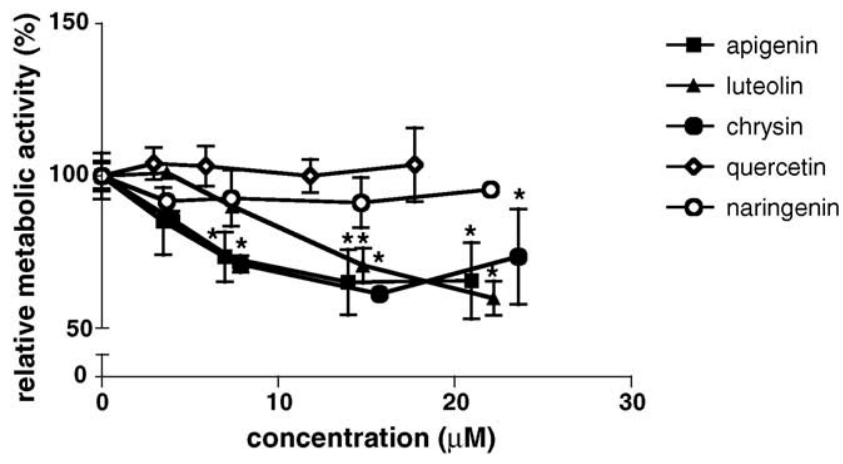

Fig. 2. The effect on metabolic activity of apigenin, chrysin, luteolin, naringenin and quercetin of LPS-stimulated PBMC measured by a WST1 assay. Metabolic activity with vehicle is set at $100 \%$. Data shown are the average of two donors, measured in triplicate and representative for a total of five human donors. The error bars shown are S.D. Statistically significant decreased metabolic activity vs. control values of $P<0.001$ is indicated with * using ANOVA with a post hoc Dunnett's $T$-test.

metabolic activity (Fig. 2). To investigate the effect of these flavones on the major cell populations in PBMC, flowcytometric analysis was performed.

\subsection{Effects of flavonoids on cell populations in PBMC}

Apigenin, chrysin and luteolin were investigated by flowcytometric analysis for their effect on the major cell populations in PBMC: monocytes/macrophages, T-lymphocytes and B-lymphocytes. Naringenin and quercetin served as negative controls since they did not inhibit metabolic activity. PBMC were stained with fluorescent monoclonal antibodies against CD19 (B-lymphocytes), CD3 (T-lymphocytes) and CD14 (monocytes/macrophages) in a double labeling with annexin $\mathrm{V}$ to detect apoptotic/dead cells. A double labeling with annexin V and propidium iodide (PI) was performed to distinguish between apoptotic and necrotic cells.

The subset of CD14+ cells from total counted cells was decreased dramatically with increasing concentrations of apigenin. Similarly, this was seen with chrysin and luteolin. With increasing concentration of the flavonoids apigenin, chrysin and luteolin, the number annexin $\mathrm{V}$ positive cells increased three-fold (Fig. 3B). In the annexin V/PI double staining, only annexin V/PI double positive cells and no annexin $\mathrm{V}$ single positive cells were detected, indicating that the increase seen in annexin V-positive cells in the CD14/annexin V staining was due to necrosis or late apoptosis (data not shown). At $32 \mu \mathrm{M}$ apigenin, the highest concentration used, non-LPS-stimulated PBMC were measured in which the number of CD14+ cells decreased as well (Fig. 5), implying that this phenomenon occurs in non-LPS-stimulated PBMC as well. Although somewhat less strong, this effect was also observed at the concentration of $16 \mu \mathrm{M}$ (not shown).

The percentage of CD14+ cells and annexin $\mathrm{V}$ positive cells remained at control levels when naringenin or quer- cetin were incubated with PBMC. CD14+/annexin V+ double positive cell numbers were not present in significant amounts (below $1 \%$ of total measured cells in all samples, not shown).

None of the five flavonoids showed an inhibitory effect on either the CD3+ cell population, or the CD19+ cell population (Fig. 4).

\section{Discussion}

Flavonoids are phenolic phytochemicals, naturally occurring in plants and abundant in particular spices, vegetables and fruits. One of the biological activities that is ascribed to certain flavonoids is their anti-inflammatory activity.

The present study reveals that monocytes/macrophages from PBMC are specifically eliminated in vitro by apigenin, luteolin and chrysin. Therefore, when using in vitro test systems with monocytes/macrophages or in vivo animal models in which flavonoids are evaluated for their antiinflammatory activity, it should be carefully examined whether effects by flavonoids, structurally similar with apigenin, are due to a cytotoxic effect on the monocytes/macrophages itself.

The observed selective elimination of monocytes/ macrophages by apigenin, luteolin and chrysin in this study, coincided with a decrease in metabolic activity and a decrease of the pro-inflammatory cytokines measured in the supernatants of LPS-stimulated PBMC. These observed effects can be related to the structural properties of the tested flavonoids (Fig. 1; Table 1), combining the data from pro-inflammatory cytokines (Table 1) with the flowcytometry data (Figs. 3 and 4). The C2-3 double bond in combination with an $\mathrm{H}$ and not an $\mathrm{OH}$ group at $\mathrm{R}_{3}$ are important features since naringenin, kaempferol, morin and quercetin, lacking those features, were not capable of inhibiting any of the pro-inflammatory cytokines up to $20 \mu \mathrm{M}$ whereas apigenin, luteolin and chrysin, equipped with those features, were capable (Table 1). Moreover, in additional experiments, apigenin, luteolin and chrysin appeared to selectively eliminate monocytes/ macrophages, whereas quercetin and naringenin had no effect on the numbers of the studied cell populations (Figs. 3 and 4). Furthermore, the $\mathrm{OH}$ groups at $\mathrm{R}_{5}$ and $\mathrm{R}_{7}$ combined with an $\mathrm{OH}$ group at $\mathrm{R}_{4}^{\prime}$ result in potent selective cytotoxic effect on monocytes/macrophages (apigenin). Substituting the $\mathrm{OH}$-group at $\mathrm{R}_{4}^{\prime}$ for an $\mathrm{H}$ atom (chrysin) results in less potency. Replacing the $\mathrm{H}$ for an $\mathrm{OH}$-group at $\mathrm{R}_{5}^{\prime}$ (luteolin) results in less potency as well. Substituting the $\mathrm{H}$ for an $\mathrm{OH}$-group at $\mathrm{R}_{6}$ results in no pro-inflammatory cytokine inhibition (scutellarein) as well as simultaneously replacing the $\mathrm{OH}$ group at $\mathrm{R}_{4}^{\prime}$ for an $\mathrm{H}$-atom (baicalein). Substituting the $\mathrm{OH}$-group at $\mathrm{R}_{7}$ for an $\mathrm{O}$-glucose-group results in no inhibition. 


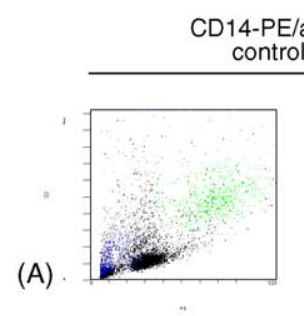

4-PE/annexin V-Fluos

control PBMC
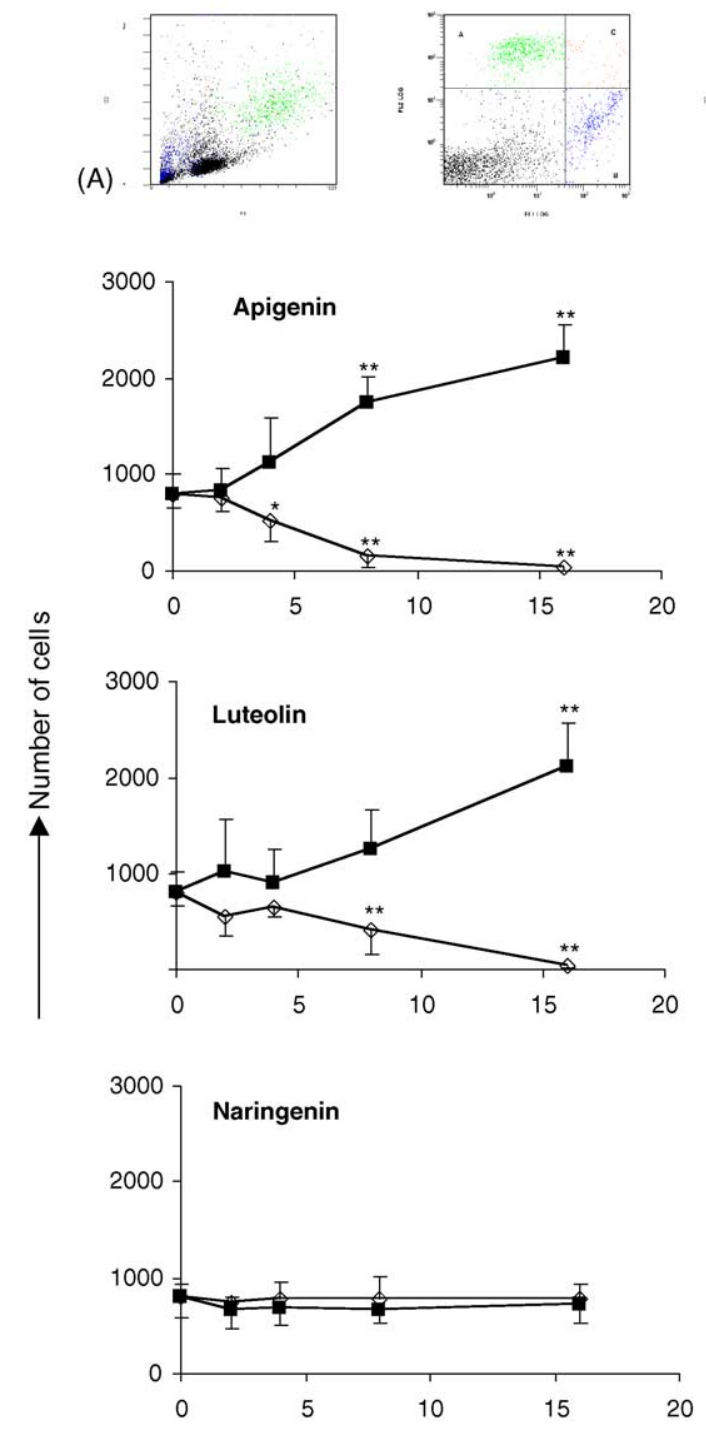
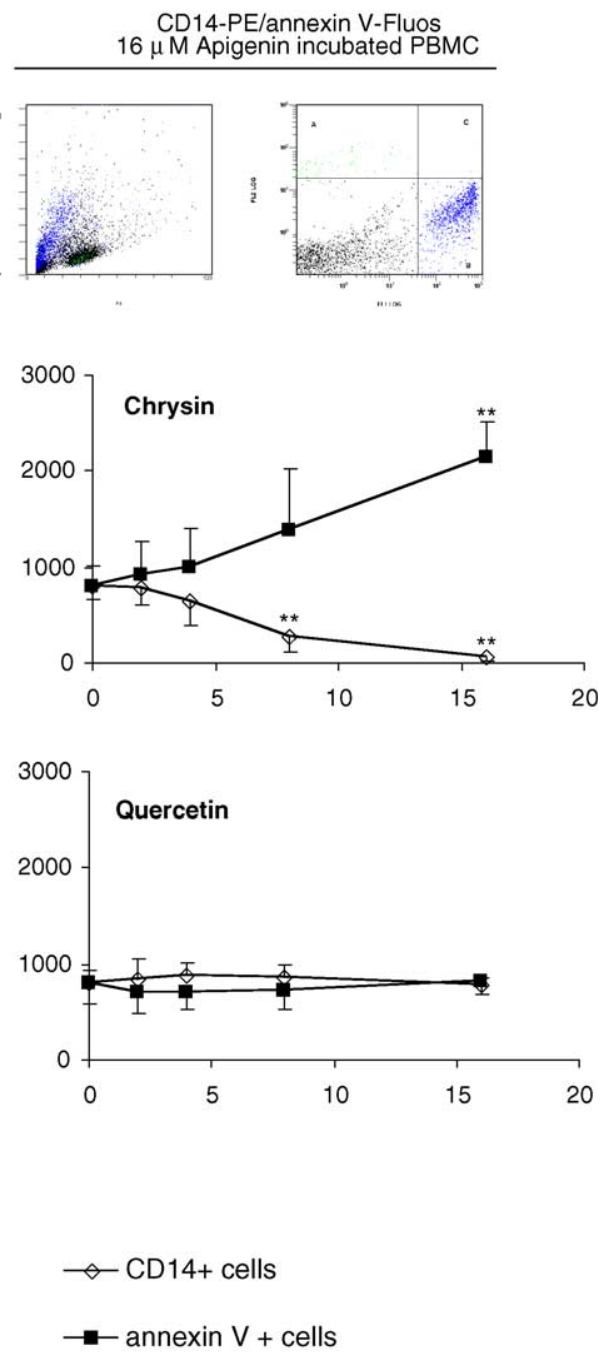

(B)

\section{Concentration in $\mu \mathrm{M}$}

Fig. 3. (A) Flowcytometrical settings for CD14-PE (monocytes/macrophages)/annexin V-Fluos staining from control and 16 $\mu$ M apigenin incubated LPSstimulated PBMC. FS/SS dotplots on the left and FL1/FL2 dotplots on the right. Regions A, B and C are CD14+ cells, annexin V+ cells and CD14+/annexin V+ cells, respectively. (B) The effect of apigenin, chrysin, luteolin, quercetin and naringenin on CD14+ cells $((\diamond)$ data from region A) and annexinV+ cells $((\square$, data from region B) in LPS-stimulated PBMC. Data shown are the average \pm S.D. of five human donors. Statistical data analysis was done using a one-way ANOVA with a post hoc Dunnett's $T$-test. A statistical significant difference compared to no flavonoid incubated is indicated by $*(P<0.05)$ and $* *(P<0.01)$.

Monocytes/macrophages are the main source of proinflammatory cytokines after LPS-stimulation of PBMC. It can be concluded that the dose-dependently decreased amounts of monocytes/macrophages caused the inhibition of the pro-inflammatory cytokines TNF $\alpha$, IL- $1 \beta$ and IL- 6 . In non-LPS-stimulated PBMC, the highest tested concentration of apigenin also depleted CD14+ cells, suggesting that this effect is not stimulation dependent (Fig. 5).

A cytotoxic effect has been reported earlier with apigenin in mouse erythroleukemia cells (MEL), but at much higher concentrations. Apigenin was found to induce cell death when incubated for more than $6 \mathrm{~h}$. Cell death increased with time at concentrations of 10, 20 and $40 \mu \mathrm{g} / \mathrm{ml}(37,74,148 \mu \mathrm{M})$ as tested by the DNA fragmentation assay [20]. A potential reason that underlies the difference of flavonoid concentration and their observed activity could be that primary PBMC are more sensitive to noxious agents than tumor cells like MEL. Therefore, primary cells can be considered more suitable than tumor cells for evaluation purposes of anti-inflammatory agents to be used in non-tumor settings, since these primary cells are similar to the cells that are present in vivo.

In vivo, apigenin has been described to inhibit the carrageenan-induced paw swelling in rats as well as 

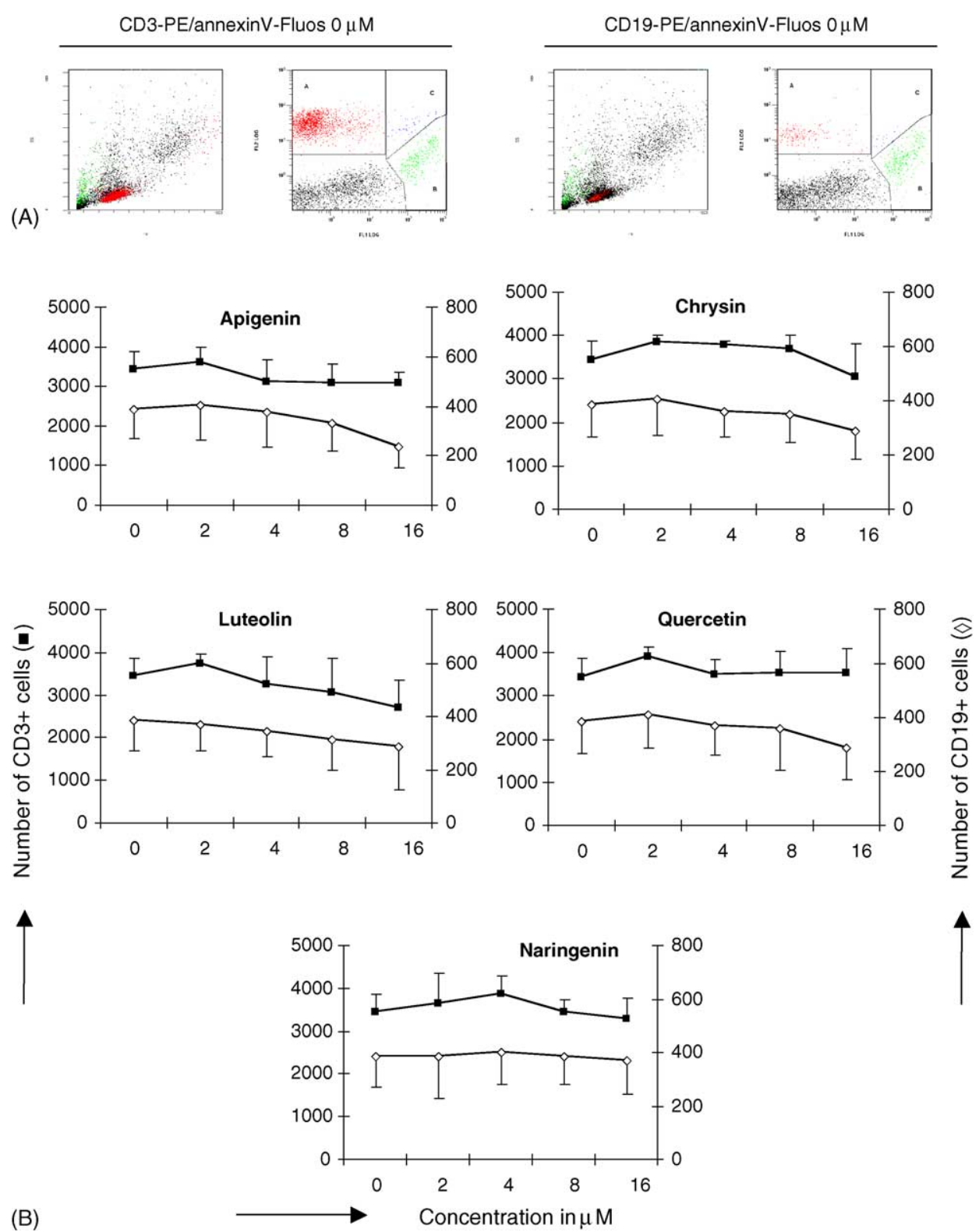

Fig. 4. (A) Flowcytometrical settings for CD3-PE(T-cells)/annexinV-Fluos and CD19-PE(B-cells)/annexinV-Fluos labeled LPS-stimulated control PBMC. FS/ SS dotplots on the left and FL1/FL2 dotplots on the right. Region A consists of either CD3+ cells or CD19+ cells. (B) Effects of apigenin, chrysin, luteolin, naringenin and quercetin on CD3+ cells and CD19+ cells in LPS-stimulated PBMC. Left $y$-axis: number of CD3+ cells ( $(\mathbf{\square}$, data from region A). Right $y$-axis: number of CD19+ cells $((\diamond)$ data from region A). $x$-axis: concentration of flavonoid in $\mu$ M. Data shown are the average \pm S.D. of five human donors. No statistical significant difference of incubated flavonoids on the number of CD3+ cells and CD19+ cells was observed using one-way ANOVA.

delayed-type hypersensitivity in mice when administered i.p. at $50 \mathrm{mg} / \mathrm{kg}$ [11] hence bypassing the gastrointestinal (GI) tract. The question whether the in vitro results from this present study are applicable for in vivo use of orally administered apigenin is relevant. Particularly, because it is suggested that flavonoid aglycons are not well absorbed in the GI-tract [21]. Moreover, data on the bioavailability of flavonoids are sparse and further research should address issues regarding the absorption, systemic availability as well as biotransformation.

In a recently published study, oral administration of apigenin at $50 \mathrm{mg} / \mathrm{kg} 1 \mathrm{~h}$ before LPS injection i.p. resulted in decreased serum levels of IL- 6 and TNF $\alpha, 90$ min after LPS injection [22], indicating that at this dose apigenin is functionally effective.

The number of circulating monocytes, however, was not investigated. Whether the findings observed in the present study could be useful for treatment of inflammation-related diseases in which monocytes/macrophages play an important role remains to be determined. Notably, in vivo, the circulating population of monocytes is dynamic, i.e. monocytes in blood are continuously supplied by the bone marrow and they migrate out into tissues as in sharp contrast to a still population of PBMC in vitro. Therefore, 

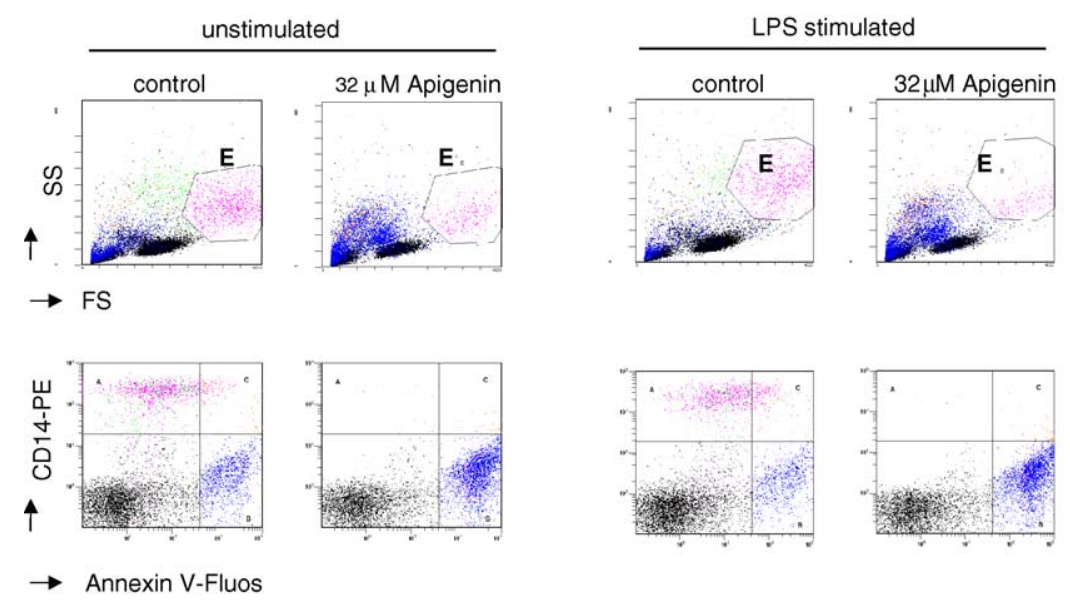

Fig. 5. Flowcytometric analysis (CD14-PE and annexin V-Fluos labeling) on unstimulated PBMC (left) and on LPS-stimulated PBMC (right) of control PBCM and of $32 \mu \mathrm{M}$ apigenin incubated PBMC. FS/SS plots (upper plots) and FL1/FL2 plots (lower plots) are shown. In the FL1/FL2 plots, nearly all CD14+ (monocytes/macrophages) cells disappear, both from the unstimulated and from the LPS-stimulated PBMC after incubation with $32 \mu \mathrm{M}$ apigenin. When selecting population $E$ in the FS/SS plots, a subset of cells at the location of the CD14+ cells in FS/SS, that population is decreased with $70 \%$ (unstimulated PBMC) and $80 \%$ (LPS stimulated PBMC).

a monocyte-eliminating effect as seen in vitro might not, or at least not to the same extent, be seen in vivo at the same concentrations of the flavonoid. However, when using these flavonoids in vivo or in cell systems with monocytes/macrophages, the observation that monocytes/ macrophages can be specifically eliminated should be taken in consideration. This specifically applies for research in which flavones, structurally similar with apigenin, are evaluated as potential anti-inflammatory agents.

In conclusion, monocytes were specifically eliminated in PBMC by apigenin, chrysin or luteolin treatment and not by quercetin or naringenin treatment. The molecular structure of the flavonoid proved to be important in resulting an (cytotoxic) effect on monocytes/macrophages in which apigenin appeared to be the most potent flavone. Further research should deal with unraveling the responsible mechanism or mechanisms that lie behind these effects.

\section{Acknowledgements}

The authors wish to thank Dr. E.A.F. van Tol for critically reading of the manuscript and Dr. R.V. Verdooren for assisting with the statistical data analysis.

\section{References}

[1] Robak J, Gryglewski RJ. Flavonoids are scavengers of superoxide anions. Biochem Pharmacol 1988;37(5):837-41.

[2] Kandaswami C, Middleton Jr E. Free radical scavenging and antioxidant activity of plant flavonoids. Adv Exp Med Biol 1994;366:35176.

[3] Bors W, Saran M. Radical scavenging by flavonoid antioxidants. Free Radic Res Commun 1987;2(4-6):289-94.

[4] Rice-Evans CA, Miller NJ. Antioxidant activities of flavonoids as bioactive components of food. Biochem Soc Trans 1996;24(3):790-5.
[5] Jankun J, Selman SH, Swiercz R, Skrzypczak-Jankun E. Why drinking green tea could prevent cancer. Nature 1997;387(6633):561.

[6] Wei H, Tye L, Bresnick E, Birt DF. Inhibitory effect of apigenin, a plant flavonoid, on epidermal ornithine decarboxylase and skin tumor promotion in mice. Cancer Res 1990;50(3):499-502.

[7] Kuo SM. Antiproliferative potency of structurally distinct dietary flavonoids on human colon cancer cells. Cancer Lett 1996;110(12):41-8.

[8] So FV, Guthrie N, Chambers AF, Moussa M, Carroll KK. Inhibition of human breast cancer cell proliferation and delay of mammary tumorigenesis by flavonoids and citrus juices. Nutr Cancer 1996;26(2):167-81.

[9] So FV, Guthrie N, Chambers AF, Carroll KK. Inhibition of proliferation of estrogen receptor-positive Mcf-7 human breast cancer cells by flavonoids in the presence and absence of excess estrogen. Cancer Lett 1997;112(2):127-33.

[10] Kawaii S, Tomono Y, Katase E, Ogawa K, Yano M. Antiproliferative activity of flavonoids on several cancer cell lines. Biosci Biotechnol Biochem 1999;63(5):896-9.

[11] Gerritsen ME, Carley WW, Ranges GE, Shen CP, Phan SA, Ligon GF, et al. Flavonoids inhibit cytokine-induced endothelial cell adhesion protein gene expression. Am J Pathol 1995;147(2):278-92.

[12] Liang YC, Huang YT, Tsai SH, Lin-Shiau SY, Chen CF, Lin JK. Suppression of inducible cyclooxygenase and inducible nitric oxide synthase by apigenin and related flavonoids in mouse macrophages. Carcinogenesis 1999;20(10):1945-52.

[13] Raso GM, Meli R, Di Carlo G, Pacilio M, Di Carlo R. Inhibition of inducible nitric oxide synthase and cyclooxygenase-2 expression by flavonoids in macrophage J774a.1. Life Sci 2001;68(8):921-31.

[14] Blonska M, Czuba ZP, Krol W. Effect of flavone derivatives on interleukin-1beta (IL-1beta) Mrna expression and IL-1beta protein synthesis in stimulated raw 264.7 macrophages. Scand J Immunol 2003;57(2):162-6.

[15] van de Loo FA, Joosten LA, van Lent PL, Arntz OJ, van den Berg WB. Role of interleukin-1, tumor necrosis factor alpha, and interleukin-6 in cartilage proteoglycan metabolism and destruction. Effect of in situ blocking in murine antigen- and zymosan-induced arthritis. Arthritis Rheum 1995;38(2):164-72.

[16] Pelletier JP, McCollum R, Cloutier JM, Martel-Pelletier J. Synthesis of metalloproteases and interleukin 6 (IL-6) in human osteoarthritic synovial membrane is an IL-1-mediated process. J Rheumatol Suppl 1995;43:109-14.

[17] Haraoui B, Pelletier JP, Cloutier JM, Faure MP, Martel-Pelletier J. Synovial membrane histology and immunopathology in rheumatoid 
arthritis and osteoarthritis. In vivo effects of antirheumatic drugs. Arthritis Rheum 1991;34(2):153-63.

[18] van der Kraan PM, van den Berg WB. Anabolic and destructive mediators in osteoarthritis. Curr Opin Clin Nutr Metab Care 2000;3(3):205-11.

[19] van de Loo FA, Kuiper S, van Enckevort FH, Arntz OJ, van den Berg WB. Interleukin-6 reduces cartilage destruction during experimental arthritis. A study in interleukin-6-deficient mice. Am J Pathol 1997;151(1):177-91.
[20] Jing Y, Waxman S. Structural requirements for differentiation-induction and growth-inhibition of mouse erythroleukemia cells by isoflavones. Anticancer Res 1995;15(4):1147-52.

[21] Ross JA, Kasum CM. Dietary flavonoids: bioavailability, metabolic effects, and safety. Annu Rev Nutr 2002;22:19-34.

[22] Smolinski AT, Pestka JJ. Modulation of lipopolysaccharide-induced proinflammatory cytokine production in vitro and in vivo by the herbal constituents apigenin (Chamomile). Ginsenoside $\mathrm{Rb}(1)$ (Ginseng) and Parthenolide (Feverfew). Food Chem Toxicol 2003;41(10):1381-90. 